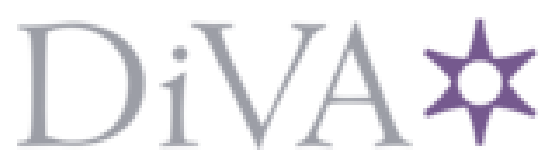

http://www.diva-portal.org

\title{
Preprint
}

This is the submitted version of a paper presented at IEEE PES General Meeting.

Citation for the original published paper:

Hooshyar, H., Mahmood, F., Vanfretti, L. (2014)

Specification and implementation of a reference grid for distribution network dynamic studies. In: 2014 IEEE PES General Meeting | Conference \& Exposition (pp. 1-5). IEEE http://dx.doi.org/10.1109/PESGM.2014.6938922

N.B. When citing this work, cite the original published paper.

(C) 2014 IEEE. Personal use of this material is permitted. Permission from IEEE must be obtained for all other uses, in any current or future media, including reprinting/republishing this material for advertising or promotional purposes, creating new collective works, for resale or redistribution to servers or lists, or reuse of any copyrighted component of this work in other works.

Permanent link to this version:

http://urn.kb.se/resolve?urn=urn:nbn:se:kth:diva-158212 


\section{Specification and Implementation of a Reference Grid for Distribution Network Dynamics Studies}

\author{
Hossein Hooshyar and Farhan Mahmood \\ EPS Department \\ KTH Royal Institute of Technology \\ Stockholm, Sweden \\ \{hossein.hooshyar, farhan.mahmood\}@ee.kth.se
}

\begin{abstract}
This paper presents the IDE4L project reference grid model developed to perform real-time hardware-in-the-loop simulations. The simulations will be carried out to study distribution network dynamics and to evaluate the techniques developed in IDE4L project for TSO/DSO interactions. Performance of the grid model is shown by sample simulation results.
\end{abstract}

Index Terms - distribution system, real-time, hardware-in-theloop, OPAL-RT.

\section{INTRODUCTION}

Funded by the European Commission's FP7 program (7th Framework Programme for Research and Technological Development), the IDE4L (Ideal Grid for All) project has recently started to define, develop and demonstrate a system of distribution network automation, IT systems and applications for active network management [1]. The project is composed of several work packages to cover different aspects of active network management. As part of work package 6 of the project, tighter integration of the operation of transmission grids (HV) with distribution grids (MV and LV) through exchange of key dynamic information between TSOs and DSOs will be investigated. The key information exchange will be performed by coupling the use of PMU data from both the HV grid and MV and LV grids (but specially HV grid) coherently. To demonstrate such tight interaction and also to evaluate the quality and relative merits of the developed techniques, there is a need to develop a reference grid model that includes a distribution network (MV and LV) and also parts of the transmission network (HV). The model will be then coupled together with PMUs, external controllers, and a co-simulation of communication networks to carry out realtime hardware-in-the-loop simulation studies.

The proposed test grids in the literature often operate at single voltage levels and also lack components such as distributed generators (DG), so they can't fulfill the requirements for studies in the IDE4L project [2-4]. This paper demonstrates the reference grid model that has been developed for this purpose. The model is implemented in MATLAB/Simulink and modified for its use with the OPAL

This work was supported in part by the FP7 IDE4L project funded by the European Commission, the STandUp for Energy Collaboration Initiative and by Statnett SF, the Norwegian TSO.

H. Hooshyar, F. Mahmood and L. Vanfretti are with KTH Royal Institute of Technology, Stockholm, Sweden (e-mail: \{hossein.hooshyar, farhan.mahmood, luigi.vanfretti\}@ee.kth.se).

L. Vanfretti is with Statnett SF, Oslo, Norway (email: luigi.vanfretti@statnett.no).

\author{
Luigi Vanfretti \\ EPS Department ; R\&D Department \\ KTH Royal Institute of Technology ; Statnett SF \\ Stockholm, Sweden ; Oslo, Norway \\ luigi.vanfretti@ee.kth.se ; luigi.vanfretti@statnett.no
}

real-time simulator. The grid topology is based on different IEEE standard test feeders including HV, MV and LV voltage levels. In the next section, the paper introduces the developed components which will be later incorporated in the grid model in Section III where the grid topology is illustrated. Section IV shows sample simulations results. Future work is listed in Section V.

\section{COMPONENT MODELS}

This section illustrates the developed components for the reference grid model. The components will be used in the next section to be incorporated in the grid model.

\section{A. Single-Phase Step Voltage Regulator (VR)}

The single-phase VR is implemented based on the model reported in [5]. The model consists of an autotransformer and a step voltage regulating relay that governs a load tapchanging mechanism. The position of the tap is controlled by the compensator circuit. The model contains a reversing switch enabling a $+/-10 \%$ regulating range, in 16 steps up and 16 steps down. Figure 1 illustrates the VR component and its dialog box. The performance of the model will be shown in Section IV.

\section{B. Static Load}

In this study, "static loads" are referred to loads that do not contain any motor. Figure 2 illustrates the developed single and three-phase static load models and the associated dialog box. As shown in the figure, the model can be chosen to be either constant current, constant impedance or constant power load; however, if the load terminal voltage drops to less than the "Operational minimum voltage", the model changes to be a constant impedance load. Note that an over/under voltage protection scheme is employed for the model which can be adjusted on the second tab. Also, in order to make the model response realistic, a random perturbation and a sinusoidal variation can be added to the base PQ of the load. This concept is illustrated in Figure 3.

\section{Dynamic Load}

We refer to "dynamic loads" as loads that have a motor. 


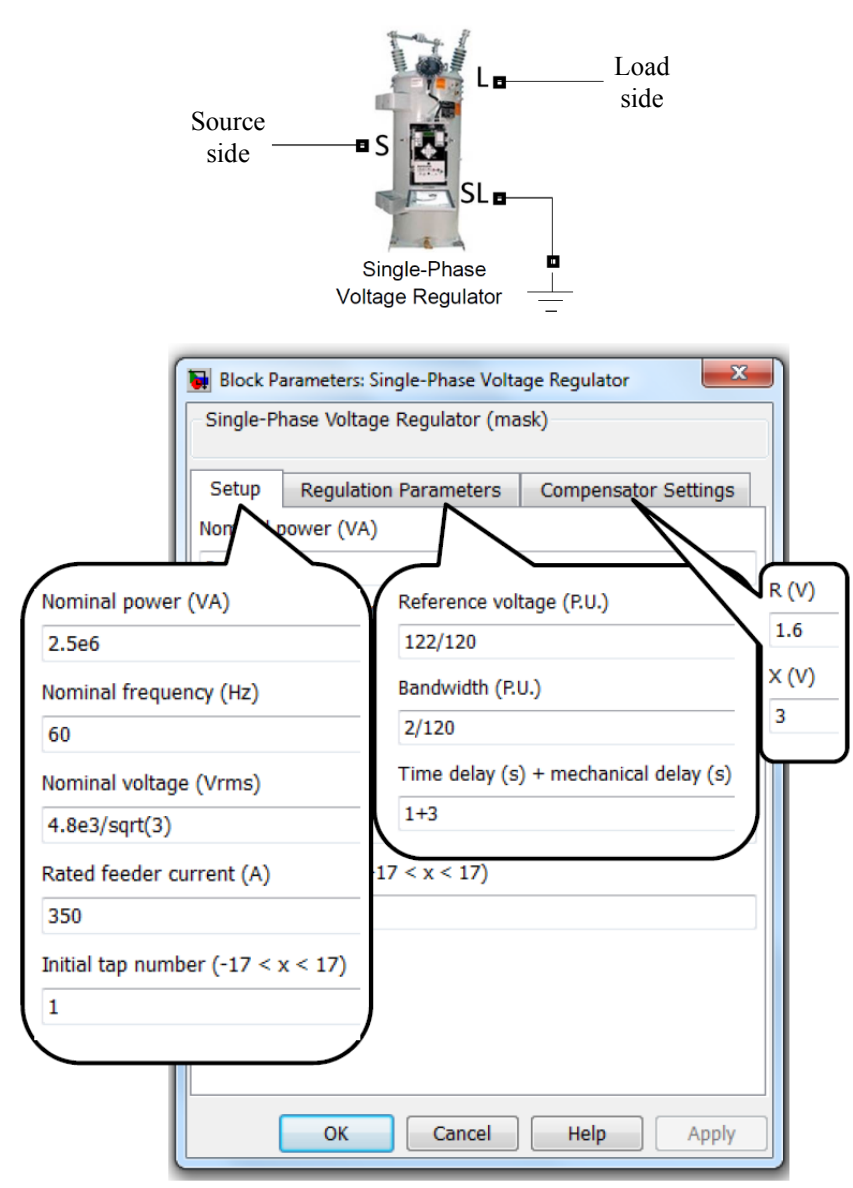

Figure 1. Developed VR component and its dialog box

Figure 4 illustrates the developed single-phase air conditioner and three-phase industrial motor load models, and also the associated dialog box. The heart of the model is an induction motor whose mechanical load torque is modeled as reported in [6]. The output voltage and current of the induction motor is scaled such that it complies with the voltage and power specified in the dialog box. As shown in Figure 4, the motor stalls if the load terminal voltage drops to less than the "Operational minimum voltage". It's also possible to set a start time at which the load will be switched on. Note that an over/under voltage protection scheme is employed for the model which can be adjusted on the second tab.

\section{Wind Farm}

The wind farm model is adopted from the doubly-fed induction generator (DFIG) model developed by OPAL-RT that uses average models for the converters [7]. The output voltage and current of the DFIG model is scaled such that the wind farm model complies with the voltage and power specified in the dialog box, as illustrated in Figure 5. An U/O voltage/frequency scheme is employed for protection against faults occurring on the grid.

\section{E. Photovoltaic (PV) System}

The PV system is simulated by adopting a model which represents the converters with average value models and
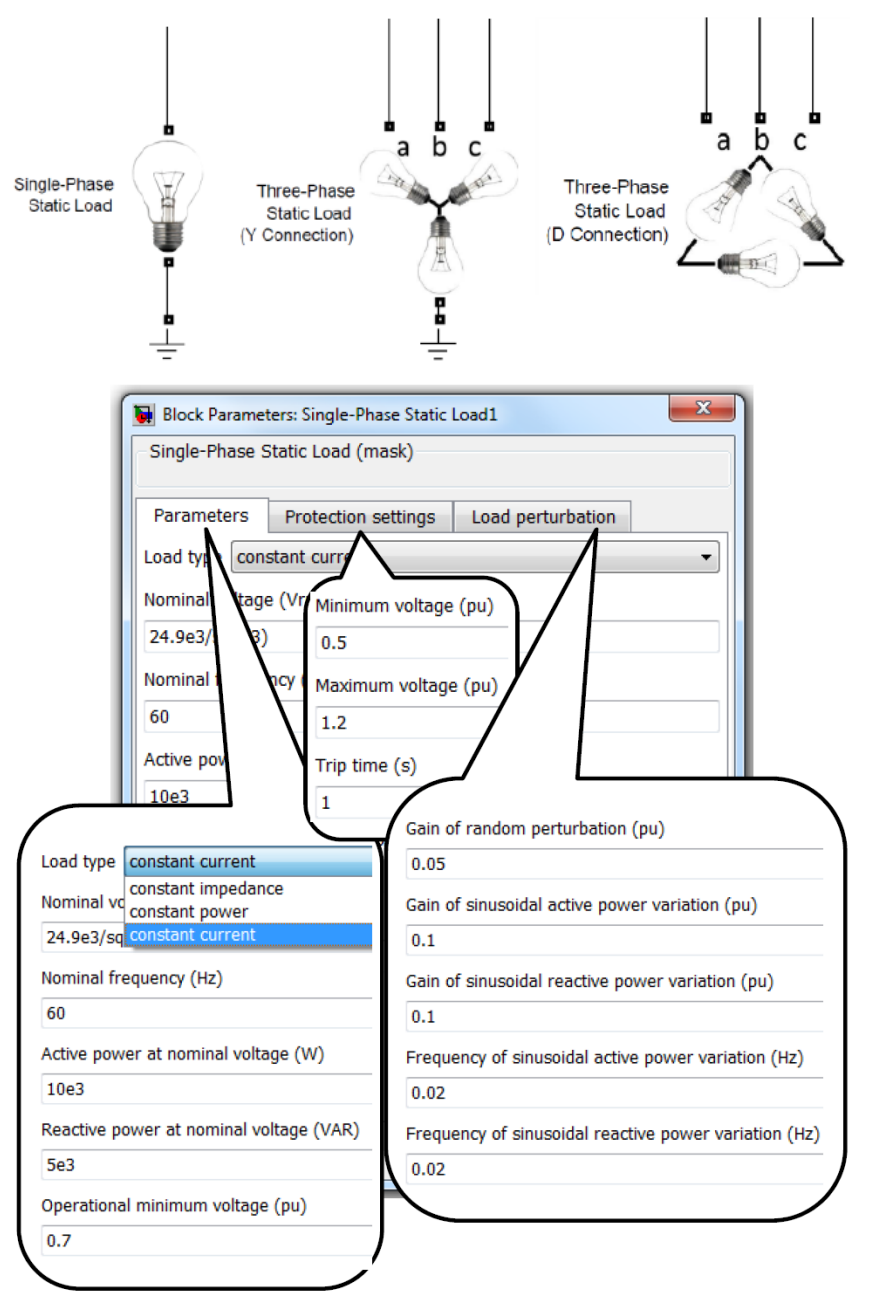

Figure 2. Developed static load component and its dialog box

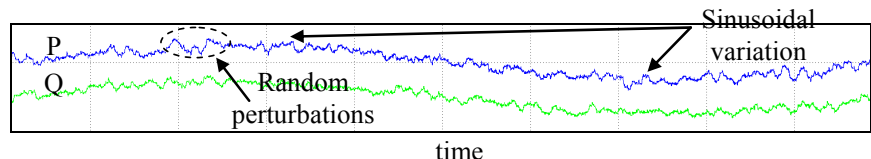

Figure 3. Static load with random perturbations and sinusoidal variation

includes maximum power point tracker [8]. Figure 6 illustrates the developed single and three-phase PV systems, and also the associated dialog box. Note that the protection scheme employed for these models are IEEE 929 compliant [9].

\section{F. Electric Power Grid (EPG)}

The "Electric Power Grid" model is developed to incorporate the dynamics of the HV grid. The heart of the model is a synchronous generator together with steam turbine and governor, excitation system, and PSS models. The output voltage and current of the synchronous generator is scaled such that it complies with the voltage and power specified in the dialog box, as shown in Figure 7. The "initial feeder consumption" on the second tab is required to initialize the signal from the governor to the synchronous generator. 

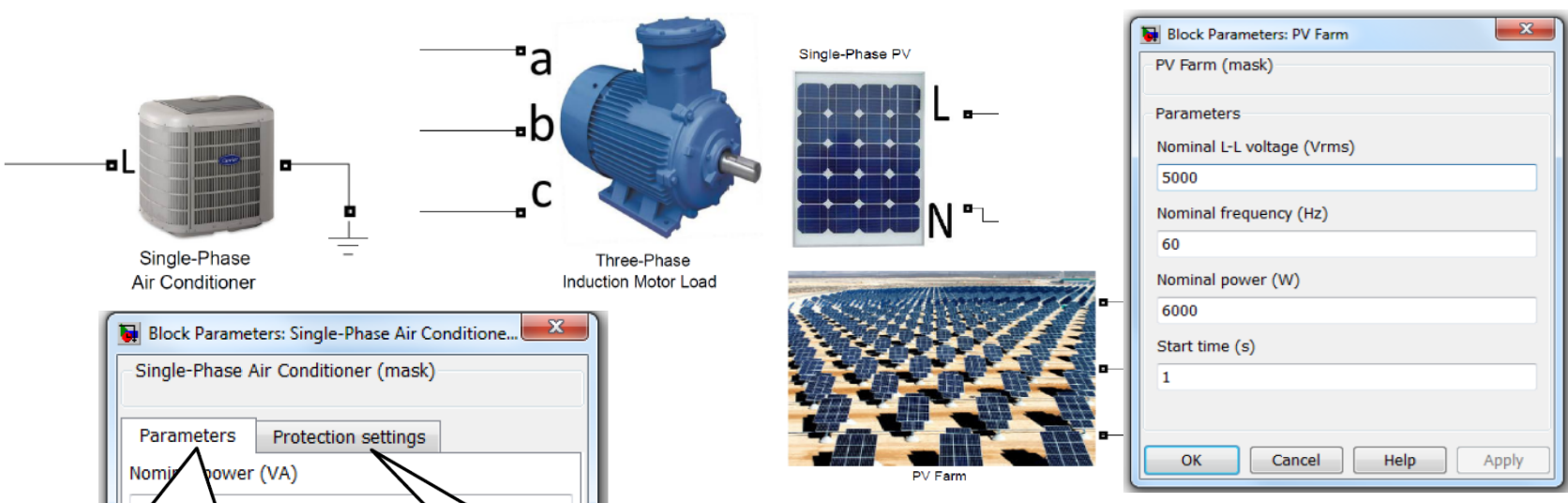

Figure 6. Developed PV system component and its dialog box

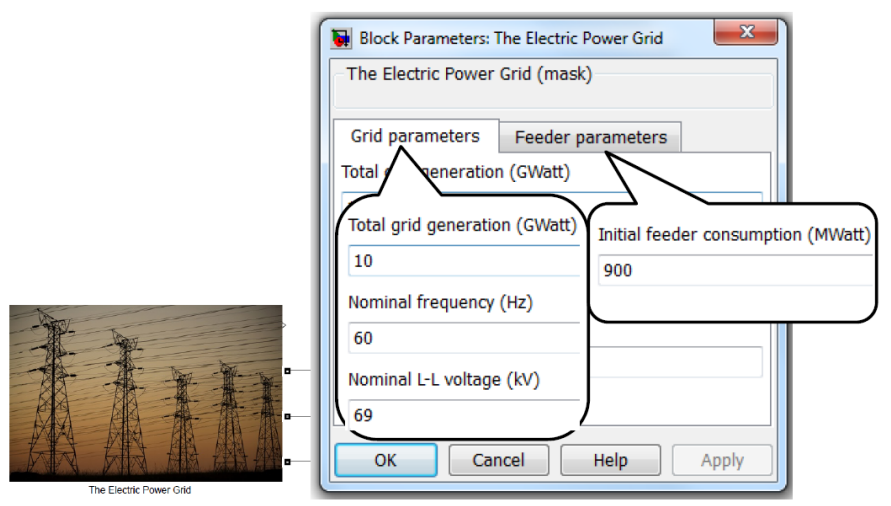

Figure 7. Developed EPG component and its dialog box

\section{SAmple Simulation Results}

Figure 9 shows sample simulation results for the test case where all dynamic loads (total of $300 \mathrm{~kW}$ ) are switched on at $\mathrm{t}=40 \mathrm{~s}$ and a 3-cycle three-phase fault is applied to the MV feeder (shown in Figure 8) at $\mathrm{t}=80 \mathrm{~s}$. As indicated in Figure 9 (subplots 2-4), at $\mathrm{t}=40 \mathrm{~s}$, the tap changers start raising the tap positions to boost the voltage. The figure also shows that after the faults occurrence at $\mathrm{t}=80 \mathrm{~s}$, a number of loads and DGs get disconnected due to insufficient voltage support (subplots 6 and 7). This results in an increase of $0.5 \mathrm{MW}(\approx 0.17$ p.u. and 1.5 MVAR $(\approx 0.5$ p.u.) demand from the HV grid. Such sudden demand variations imply the need for tighter operation and coordination of the transmission and distribution networks.

\section{FUTURE WORK}

The reference grid model is being improved by adding other components such as battery storage system, feeder protection including protective relays and reclosers, and diesel generators.

\section{REFERENCES}

loads are replaced by dynamic loads. DGs have been distributed throughout the whole grid as illustrated in figure 8 . As the figure shows, due to high computational burden of the model, it has to be distributed on 9 cores of the OPAL-RT simulator to comply with real-time simulation constraints.

[1] http://www.ide4l.eu

[2] http://www.ewh.ieee.org/soc/pes/dsacom/testfeeders/index.html

[3] W. H. Kersting, "A comprehensive distribution test feeder," IEEE PES T\&D Conf., 2010. 
[4] J.S. Savier, D. Das, "Impact of network reconfiguration on loss allocation of radial distribution system," IEEE Trans. on Pow. Del., vol. 22, no. 4, pp. 2473-2480, Oct. 2007.

[5] W. H. Kersting, "Distribution Feeder Voltage Regulation Control," IEEE Trans. on Ind. App., vol. 46, no. 2, pp. 620-626, Mar./Ap. 2010

[6] B. Lesieutre, "Phasor Modeling Approach for Single Phase A/C Motors," IEEE PES C\&D of EE Energy, 2008.
[7] http://www.opal-rt.com/demo-application/10-wind-turbine-farm-andpower-grid

[8] H. Hooshyar, M. E. Baran, "Fault analysis on distribution feeders with high penetration of PV systems", IEEE Trans. Power Sys, vol. 28, no. 3, pp. 2890-2896, Aug., 2013.

[9] IEEE 929, "IEEE recommended practice for utility interface of photovoltaic (PV) systems", 2000.
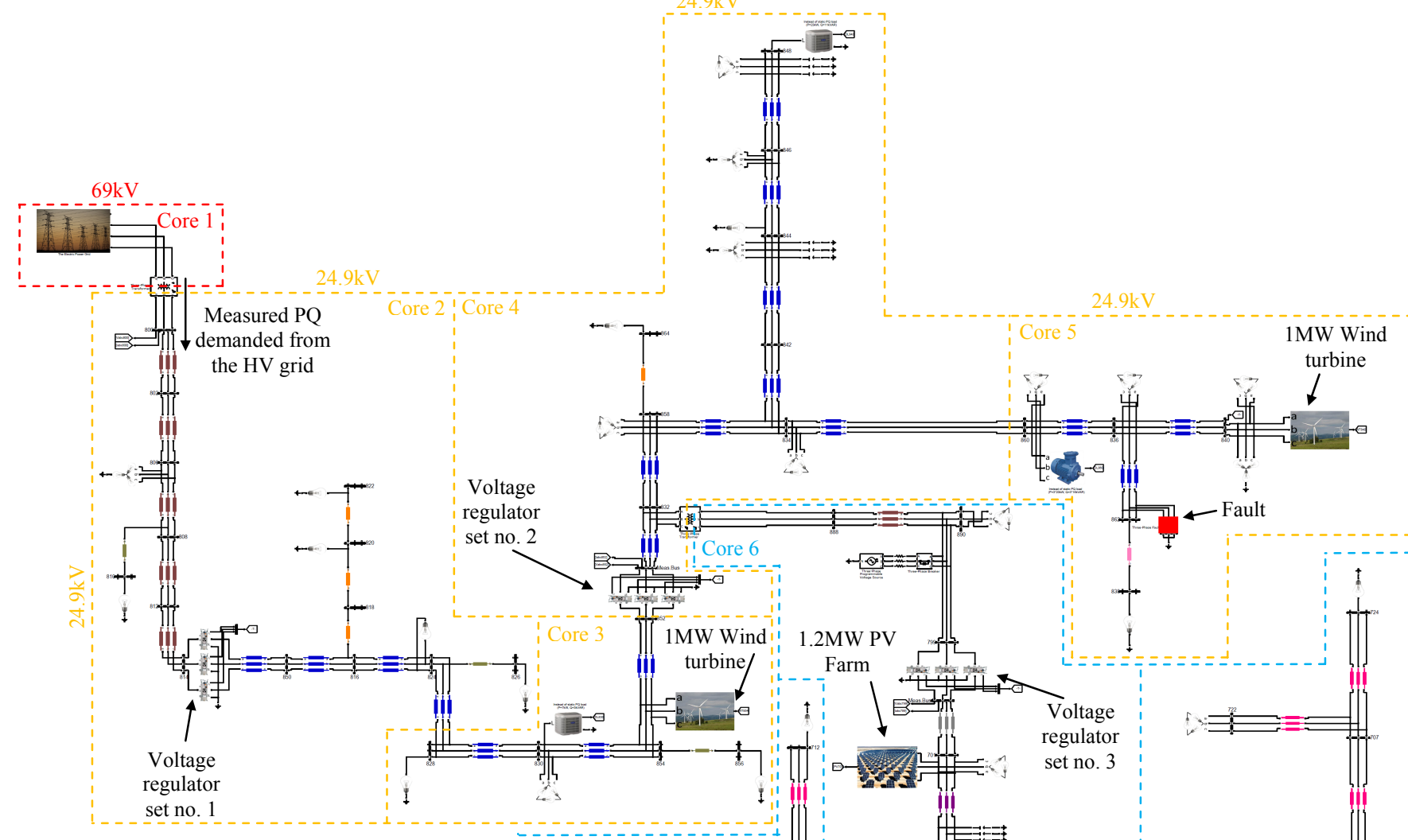

regulator

set no. 2
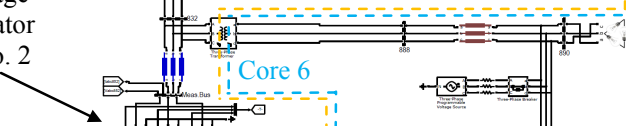

$1 \mathrm{MW}$ Wind
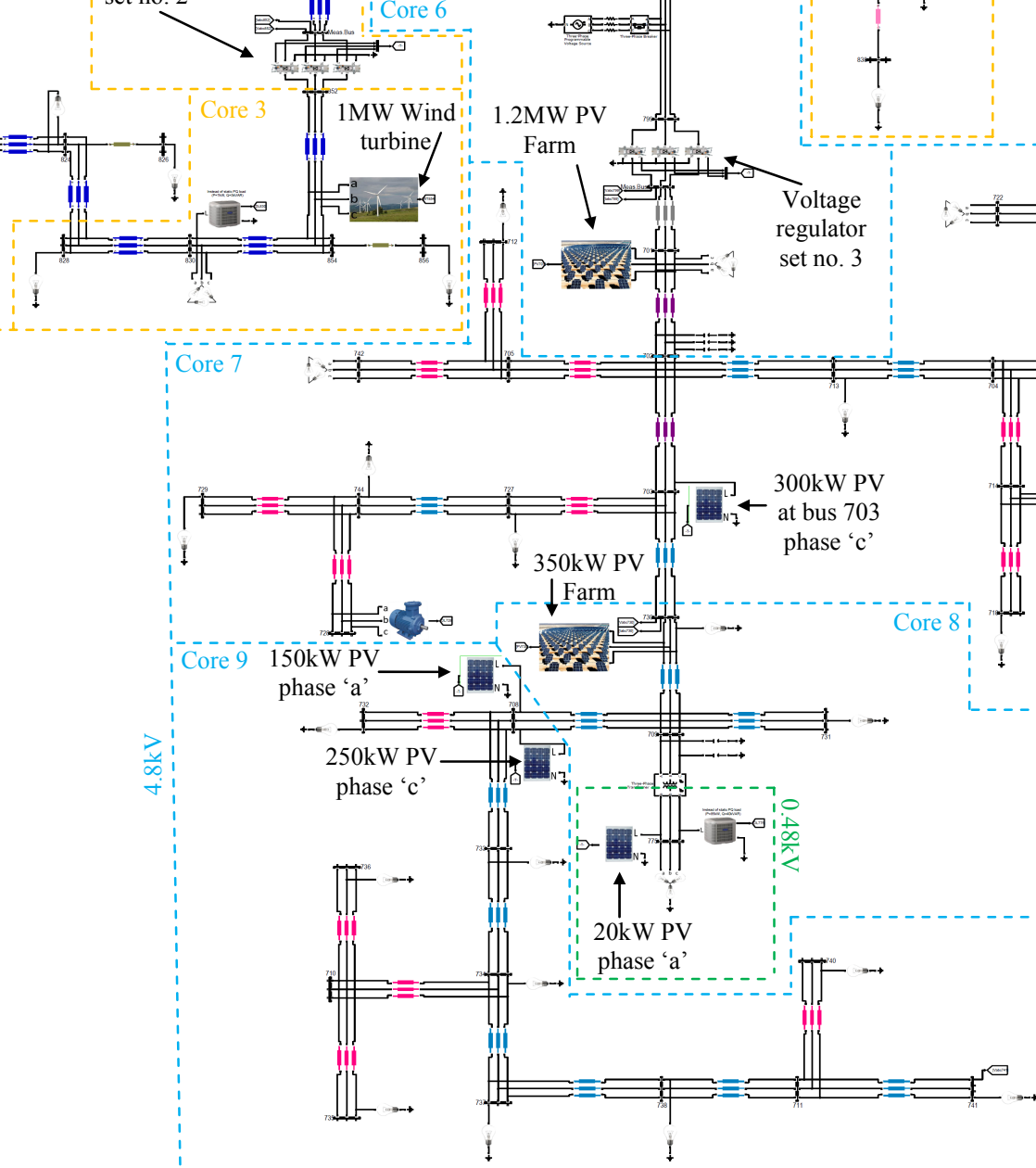

$4.8 \mathrm{kV}$

Figure 8. The reference grid model distributed on 9 cores of OPAL-RT real-time simulator 


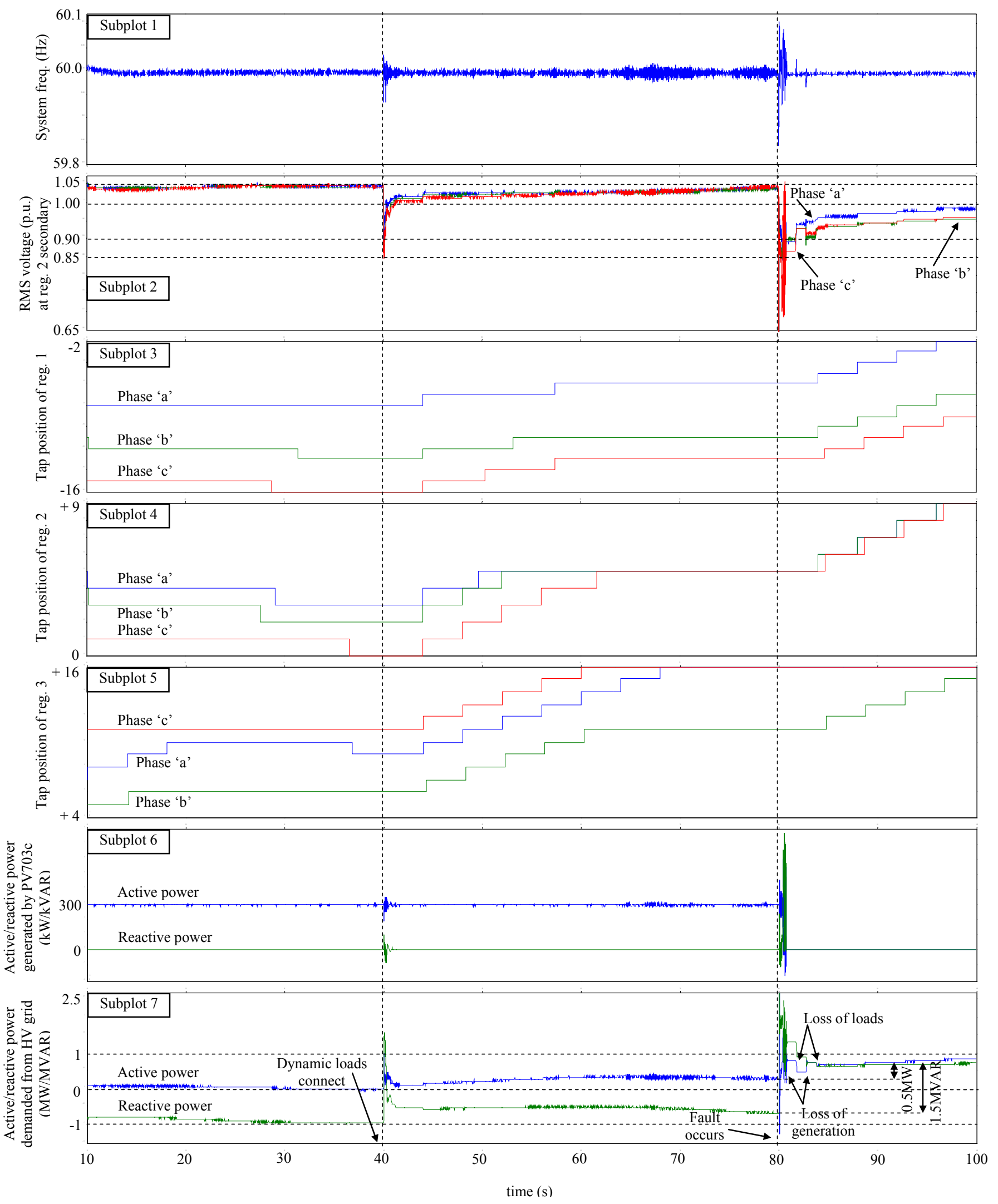

Figure 9. Sample simulation results 